\title{
Limiting "evergreening" for a better balance of drug innovation incentives
}

\author{
Matthew B. Stanbrook MD PhD
}

$\mathrm{T}$ he global pharmaceutical industry's most important new development this year may have taken place in the courtroom rather than in a laboratory. In April 2013, India's Supreme Court denied a patent on a new version of the drug imatinib (used primarily in the treatment of certain forms of leukemia) to its manufacturer Novartis, arguing that it was not different enough from the previous version. ${ }^{1.2}$ This unprecedented decision will likely preserve the availability of much cheaper generic versions of imatinib and other drugs, not only for India but also for the many developing nations India supplies with affordable pharmaceuticals. Lessons may be taken from this in other countries, particularly in affluent nations like Canada.

At issue in the Indian case was "evergreening," a now widespread practice by the pharmaceutical industry designed to extend the monopoly on an existing drug by modifying it and seeking new patents. ${ }^{2}$ Currently, half of all drugs patented in Canada have multiple subsequent patents, extending the lifetime of the original patent by about 8 years. ${ }^{3}$ Manufacturers, in defence of these practices, predictably tout the advantages of new versions of their products, which often represent more potent isomers or salts of the original drugs, longerlasting formulations or improved delivery systems that make adherence easier or more convenient. But the new versions are by definition "me too" drugs, and demonstration that the resulting incremental benefits in efficacy and safety are clinically meaningful is often lacking. Moreover, the original drugs have often been "blockbusters" used for years to improve the health of millions of patients. It seems hard to argue convincingly why such beneficial drugs require an upgrade, often just before their patents expire.

Rather than the marginal benefits accrued from tinkering with already effective agents, patients worldwide are in desperate need of new classes of pharmaceuticals for the great many health conditions for which treatments are presently inadequate or entirely lacking. But developing truly innovative drugs is undeniably a high-risk venture. It is important and necessary that pharmaceutical companies continue to take these risks, because they are usually the only entities with sufficient resources to do so. Therefore, companies must continue to perceive sufficient incentives to continue investing in innovation. Indeed, there is evidence that the prospect of future evergreening has become part of the incentive calculation for innovative drug development. ${ }^{4}$
But surely it is perverse to extend unpredictably a period of patent protection that the government intended to be clearly defined and predictable, and to maintain incentives that drive companies to divert their drug-development resources away from innovation. Current patent legislation may not be optimal for striking the right balance between encouraging innovation and facilitating profiteering. Given the broad societal importance of patent legislation, ongoing research to enable active governance of this issue should be a national priority.

In the last decade, Canada's laws have been among the friendliest toward evergreening in the world. ${ }^{5}$ We should now reflect on whether this is really in our national interest. Governments, including Canada's, would do well to take inspiration from India's example and tighten regulations that currently facilitate evergreening. This might involve denying future patents for modifications that currently would receive one. An overall reduction in the duration of all secondary patents on a therapy might also be considered. Globally, a more flexible and individualized approach to the length of drug patents might be a more effective strategy to align corporate incentives with population health needs.

Limits on evergreening would likely reduce the extensive patent litigation that contributes to the high prices of generic drugs in Canada. ${ }^{3}$ Reducing economic pressure on generic drug companies may facilitate current provincial initiatives to lower generic drug prices. As opportunities to generate revenue from evergreening are eliminated, research-based pharmaceutical companies would be left with no choice but to invest more in innovative drug development to maintain their profits.

\section{References}

1. Novartis $A G$ v. Union of India \& others, (2013). Civil Appeal Nos. 2706-2716 OF 2013 (Arising out of SLP(C) Nos. 20539-20549 OF 2009). Available: http://supreme courtofindia.nic.in/outtoday/patent.pdf (accessed 2013 July 2).

2. Collier R. Drug patents: the evergreening problem. CMAJ 2013;185:E385-6.

3. Lexchin J. Canada's Patented Medicine Notice of Compliance regulations: Balancing the scales or tipping them? BMC Health Serv Res 2011;11:64.

4. Gaudry KS. Evergreening: a common practice to protect new drugs. Nat Biotechnol 2011;29:876-8.

5. Sibbald B. Rules that extend drug patents face challenge. CMAJ 2003;169:950.

Competing interests: See www.cmaj.ca/site/misc/cmaj_staff.xhtml

Affiliation: Matthew Stanbrook is Deputy Editor, Scientific, CMAJ.

Correspondence to: $C M A J$ editor, pubs@cmaj.ca

CMAJ 2013. DOI:10.1503/cmaj.130992 